\title{
Архаические рассуждения об иерархии и власти (о книге А. П. Ермилова «Власть и экономические отношения: деятельностный подход»)
}

П.н. ТЕсля, кандидат экономических наук, Новосибирский государственный технический университет, Новосибирский государственный университет. E-mail: teslia.pavel@gmail.com

Обсуждается концепция системы социально-экономических отношений, выведенных из отношений власти (господства - подчинения). Автор рецензируемой книги развивает систему категорий политической экономии, опираясь на методологию К. Маркса, привнося в нее ряд новых элементов и изымая из нее те элементы, которые, по его оценке, не существенны. Критическое рассмотрение рецензируемой книги показывает ее сильные и слабые стороны. Концепция автора оценена с точки зрения требований методологической корректности, а также путем сравнения с альтернативными подходами. Положенный в основу рассмотрения изучаемых вопросов деятельностный подход приводит автора к оригинальным результатам, отличным от общепризнанных. В рецензии обсуждаются объясняющая сила предложенной автором концепции, ее полнота и непротиворечивость.

Ключевые слова: производственные отношения, господство - подчинение, иерархии, власть, институты, политическая экономия, мэйнстрим, поведенческая и экспериментальная экономика

Книга А.П. Ермилова [Ермилов, 2017; здесь и далее ссылки на нее будут приводиться в тексте в круглых скобках с указанием страниц] написана по канонам уже почти исчезнувшего жанра исторического материализма. Автор назвал одной из своих целей реабилитацию политической экономии как истинной науки в противовес мэйнстрим-экономике, занимающейся, как считает автор, не свойственными для экономической теории вопросами.

Ключевая идея книги сводится к следующему: все общественные отношения, в том числе экономические, порождаются отношениями господства и подчинения одних людей другими. Люди совершают свою деятельность на основе мотивации, индуцированной их местом в иерархии власти и навязанной властителями. Именно властью и мотивацией должна заниматься экономическая теория, а политической экономии принадлежит главная роль в этих исследованиях. 
Автору явно близка методология классической марксистской политической экономии. Об этом свидетельствуют и термины, которыми он оперирует, и способ изложения, типичный для марксистов.

Следует отметить ярко выраженный индивидуальный авторский стиль. К сожалению, он нелегок, и читателю приходится прилагать много усилий к тому, чтобы постичь суть сказанного. Цитируя Н.В. Гоголя, можно сказать, что у А.П. Ермилова «все было без пошатки, располагалось в каком-то крепком и неуклюжем порядке», «прочно, неуклюже в высочайшей степени». Стилистические и терминологические дебри становятся серьезным препятствием тому, чтобы книгу прочитало много людей. А книга между тем достаточно примечательна и заслуживает того, чтобы с ней познакомились хотя бы потому, что она относится к научной дисциплине философии экономики, сравнительно новой для российских студентов и ученых.

Обсуждение книги, автора которой в дальнейшем рецензент для краткости (а не от неуважения) будет называть А.Е., организовано следующим образом: сначала - о том, что в книге есть, затем - о том, чего нет, но должно быть, и наконец - почему эта книга полезна.

\section{Что в книге есть}

В первой главе А.Е. тщательно описывает методологический прием, который будет использоваться на протяжении всей книги. Чтобы показать свое точное место в академическом сообществе, А.Е. прибегает к обильному цитированию. Доля цитат в объеме первой главы превышает $50 \%$. Ссылаясь на авторитеты, А.Е. подробно описывает так называемый деятельностный подход. Суть его в том, что деятельность является основным объяснительным принципом исследования общества. Почему работа с деятельностью так важна как методический прием? А.Е. отвечает, цитируя очень многих. Рецензенту более всего понравилась цитата классика австрийской школы экономической мысли Людвига фон Мизеса: «Человеческая деятельность это одно из средств осуществления изменений, она - элемент космической активности и становления. Поэтому она является законным объектом научного исследования. Так как ее невозможно (по крайней мере, в современных условиях) свести к своим причинам, она должна рассматриваться как конечная данность и изучаться как таковая». Вместе с тем, как говорит другой признаваемый и цитируемый А.Е. экономический философ Э.Г. Юдин, «кажется сомнительным, чтобы объяснительная схема какой-то конкретной научной дисциплины могла быть целиком сведена к одному-единственному понятию, пусть даже внутренне богатому и расчлененному» ${ }^{1}$.

К сожалению, в этой главе А.Е. не обращает внимания на то, что деятельностный подход, популярный среди российских экономических философов, очень сильно коррелирует, если не совпадает, с так называемым бихевиоризмом. В этом нет ничего зазорного, однако, отметив близость с бихевиоризмом и обсудив его, А.Е. удалось бы избежать вопросов относительно методической обоснованности ссылок на актуальную деятельность. Дело в том, что узкая трактовка бихевиоризма исключительно как концепции непосредственной, живой деятельности, является ошибочной предпосылкой при рассмотрении вопросов экономических отношенийㄹ. А между тем именно последние являются главным предметом рассматриваемой книги.

Поясним. Согласно А.Е., получается, что экономическое отношение - это всегда некое сознательное действие, деятельность, однако экономическое отношение в реальности не всегда приводит к деятельности и не всегда в нем выражается. В частности, отношение к властям может быть пассивным, бездеятельным. Смирение часто оказывается вынужденным либо внушенным состоянием. Однако часто за смирением скрываются нарастающее противоречие, фрустрация, конфликт и потенциальный бунт; если теория этого не учтет, то она лишится предсказательной силы.

Во второй главе А.Е. увлечен цитированием в меньшей степени, чем в первой, здесь только $30 \%$ текста принадлежат другим авторам. Начинает эту главу А.Е. со ссылки на якобы доказанный факт, что «совместность (социальность) деятельности является универсальным феноменом животного мира». Второе сильное утверждение: «важнейшим атрибутом животного мира является

Это высказывание вполне может быть обращено в упрек самому автору, ведь его подход реализует именно этот принцип - выведение всей системы общественных отношений из отношений власти и подчинения.

Этот момент подробно обсуждается в первой главе одной из работ, приведенных в списке литературы в рецензируемой книге [Льюкс, 2010]. 
иерархия, стремление к доминированию или подчинению в стаде и в обществе» (С. 59).

А.Е. поясняет близость человеческого общества к животному миру следующим образом: «Превращение первобытного стада в первобытное общество как раз и означало преобразование основанных на инстинктах животных (природных) механизмов социальности в механизмы общественные, основанные на использовании развивающегося общественного сознания» (С. 60). Что является объединяющей социализирующей основой животного мира, в который, как полагает А.Е., входит составным элементом и человеческое общество? Ответ: иерархия, система господства и подчинения. Любое сообщество, в животном ли мире или в человеческом обществе, строится по принципу пирамиды: верхние слои управляют нижними, и чем ближе к вершине, тем меньше становится господствующих и сильнее их власть.

Надо заметить, что приводимые А.Е. цитаты не всегда содержат непротиворечивые взгляды на обсуждаемый вопрос и не все согласуются с его позицией. Вот, например, две цитаты про иерархии и координацию из биолога В. А. Энгельгардта (С. 65).

1. «Ведущими началами в биологических иерархиях выступают элементы координирования и кооперации, а не доминирование и подчиненность».

2. «В области социальных структур, откуда по существу и заимствовано понятие об иерархии, в средневековом строе, с его королем, князьями, полководцами, рыцарями, воинами, ремесленниками, сельскими тружениками, на первое место выступали элементы власти, прав, повеления, господства, направленные всегда однозначно от высших членов иерархии к низшим, то есть главенство было началом подчиненности».

Как это понимать? В человеческом обществе меньше ценят сотрудничество (товарищество, братство) и больше полагаются на подавление, подчинение слабого сильным? Животный мир более гуманен, чем человеческий? Невольно вспоминаешь ходячую фразу, которую приписывают то Чехову, то Гейне, то Шанель: «Чем лучше я узнаю людей, тем больше мне нравятся собаки». К вопросу об альтруизме в животном мире и роли координации и кооперации в человеческой экономике мы обратимся еще раз во втором разделе этой рецензии.
Что является источником власти? А.Е. отвечает: неравенство в распределении ресурсов. Сильный принудит слабого, умный обманет, уговорит или сагитирует глупого, владелец ценного и редкого ресурса (земли и капитала) допустит к нему невладельца за плату.

Власть господ распространяется не только на материальную, но и на духовную сферу. Господа не только принуждают, побуждают, понуждают, но и мотивируют своих слуг. Господа формируют у слуг универсальные ценности и цели и с выгодой играют на этом.

Центральный вид экономических отношений, отношения собственности, возникают в результате действия отношений господства и подчинения. Отношения собственности, в свою очередь, являются предпосылками возникновения у членов общества того или иного статуса. А поскольку статусы образуют иерархию, то те, кто находится на более высоких ступенях статусной пирамиды, берут на себя функции управления социальной деятельностью данного общества. Если по какой-то причине в узловых позициях вертикали властной пирамиды не оказывается адекватных властителей (альфа-особей. - П.Т.), то общество становится неустойчивым: оно либо не сформировывается (так у автора. - П.Т.) либо разваливается (С. 95).

Поскольку власть - это центральная тема книги, А.Е. затрачивает довольно много усилий на то, чтобы определить методы (способы, средства) осуществления власти: жесткие и мягкие, принуждение, понуждение, побуждение, насилие, командование, убеждение, манипуляции, авторитет.

Третья глава называется «Две стороны деятельности и два вида социальных отношений». Она самая скучная и схоластическая, однако, она важна для понимания открытой А.Е. двойственности производственных отношений. Здесь он рассказывает нам, что «каждая деятельность является формой взаимодействия человека с природой» (С. 118), что «общество выступает причиной, генератором, создателем общественных отношений, и одновременно оно же является следствием, результатом их функционирования» (С. 121), что «нет общественных отношений - нет деятельности» (С. 125).

Принципиальный момент третьей главы таков: вводятся разграничения между технологическими и общественными 
отношениями. Технологические отношения - это когда люди, как лишенные мотивации живые механизмы, взаимодействуют друг с другом в технологическом процессе, исполняя отдельные трудовые операции, соблюдая технические регламенты. Общественные же отношения - это отношения господства - подчинения, они находятся под воздействием мотивов (в некоторых местах А.Е. отождествляет мотивы и общественные отношения). Эти два типа отношений, технические и общественные, А.Е. считает взаимосвязанными.

Чтобы читателю стало понятно, о чем речь, А.Е. приводит пример охоты на мамонта в первобытной общине, единственный, кстати, который сквозным образом проходит через несколько разделов книги (других связей излагаемого материала с реальностью, хотя бы воображаемой, А.Е. на протяжении всей книги почти полностью избегает). «Члены общины владеют навыками исполнения необходимых в процессе охоты действий, то есть понимают, каковы должны быть естественные (технологические) отношения между ними в процессе этой деятельности. Таким образом, община имеет потенциальную возможность осуществления деятельности. Когда же эта возможность превращается в реальность? Тогда, когда в общине имеются специальные механизмы, а именно, действующая система господства и подчинения, благодаря которой отдельные члены общины имеют право приказать другим приступить к осуществлению определенных действий, а эти последние принимают на себя обязанность данные приказы исполнять» (С. 137).

Технологические отношения у А.Е. не являются ни экономическими, ни тем более производственными. Мотивация же, по мнению А.Е., - это феномен не технологических, а экономических отношений. Как только человек вступит в технологический процесс, мотивы замирают. Технологические отношения - это обработка природы людьми, общественные-это обработка людей людьми (С. 142).

В четвертой главе А.Е.систематизирует и классифицирует хозяйственные отношения, при этом не поясняя, являются они экономическими или технологическими, или и теми и другими.

Для целей классификации хозяйственных отношений он вводит три группы категорий. Первая - это виды деятельности, вторая - сферы деятельности и третья-процессы. Наполнение всех этих категориальных групп одно и то же, а именно: 1) собственно производство; 2) обмен и 3 ) потребление. Так, производство - это и вид деятельности, и сфера деятельности, и процесс. Аналогично - и все остальное. Обращаем внимание, что в каждую из этих трех групп попадает только по три категории, а не по четыре.

Что же побудило А.Е. ввести эти классификации? По всей вероятности, это сделано для того, чтобы внести вклад, точнее, изъятие из марксистской политической экономии. Те, кто читал «Введение в критику политической экономии» Маркса и его «Экономические рукописи 1857-1859 гг.», должны помнить определение, которое классик дал производству, распределению, обмену и потреблению. В частности, сказано, что производство как таковое образует основу для существования общества. Маркс подробно обсуждает тот факт, что производство дает продукт, который подлежит распределению в виде вознаграждения участников процесса производства; этот продукт поступает в сферу обмена, где он обращается между участниками процесса производства и, наконец, потребляется в сфере потребления. Далее Маркс рассуждает о том, что производство одновременно является и распределением факторов производства между видами деятельности, и обменом деятельностью между участниками процесса производства, и потреблением факторов производства, в результате которого последние уничтожаются, но это приводит к созданию продукта. Наконец - что и распределение является одновременно производством, обменом и потреблением, и потребление - также тождественно производству, поскольку суть потребления - это воспроизводство человека как фактора производства.

А.Е. пересказом или цитированием приведенных диалектических рассуждений Маркса не занимается, он делает другое упраздняет сферу распределения. Причина, как он считает, в том, что «в хозяйстве общества... отсутствуют такого рода "распределительные” хозяйственные ячейки» (С. 159). Подразумевается, что распределение как фаза широко трактуемого производства в понимании Карла Маркса осуществляется в рамках системы, сконструированной А.Е., как бы само собой. Неясно, правда, поскольку нет «распределительных ячеек», существуют ли в такой системе отношения распределения как таковые? А если нет, то на каком основании построены взаимоотношения властителей 
и их подчиненных. Вспомним, что, согласно построениям А.Е., экономической основой власти является неравномерное распределение ресурсов, в особенности - собственности на материальные факторы производства.

Обозревая построенный усилиями А.Е. категорийный аппарат, опять вспоминаешь Н.В. Гоголя: «Было заметно, что при постройке его хозяин беспрестанно боролся со вкусом зодчего. Хозяин приказал одну колонну сбоку выкинуть, и оттого очутилось не четыре колонны, как было назначено, а только три».

В пятой главе А.Е. берется за детальное рассмотрение технологических и производственных отношений. Здесь он вводит понятие производственной ячейки. По-видимому, это аналог того, что в экономической литературе принято называть фирмой. «Производственная ячейка представляет собой совокупность факторов производства и работников (рабочая сила)... В составе трудовой деятельности выделяются две технологические роли: (1) управляющих - руководителей и организаторов процесса труда, (2) непосредственных производителей, носителей живого труда» (С. 198-199).

Отношения между управляющими и управляемыми в процессе производства А.Е. определяет как разновидность господства и подчинения. Здесь у читателя возникает вопрос: каким образом в чисто технологической сфере, то есть там, где, согласно утверждению А.Е., отсутствуют общественные отношения, все-таки существуют отношения власти?

Что мотивирует участников производственного процесса? У подчиненных это страх перед бедностью, у хозяев - осуществление производственного процесса (С. 206). В этом месте мы вновь наблюдаем довольно сильное расхождение между представлениями А.Е. и Маркса. По Марксу, производство само по себе и капиталистов, и их агентов, то есть управляющих, интересует лишь постольку, поскольку в результате кругооборота капитала создаются стоимость и прибавочная стоимость. Именно последняя и интересует, то есть мотивирует и капиталистов, и управляющих, согласно концепции Маркса.

Участники процесса производства различаются по признаку владения или невладения собственностью. Кроме того, они могут быть лично свободными или несвободными. Введя это признаки, А.Е. формирует четыре возможные комбинации свобод и несвобод: 1) личная свобода, основанная на вещной свободе, 2) личная свобода, основанная на вещной зависимости, 3) личная зависимость, основанная на вещной свободе и 4) личная зависимость, основанная на вещной зависимости. На базе этих комбинаций А.Е. в дальнейшем производит классификации крупных исторических эпох. Какой-то из комбинаций соответствует эпоха рабовладения, какой-то - феодализм, какойто - капитализм и т.д.

А.Е. пишет: разновидностью власти являются отношения собственности. Господа, пользуясь властью, создают формы собственности. Собственность - это причина власти. В эпоху племенной собственности право устанавливать отношения собственности возникало как следствие места племенной знати в системе отношений господства и подчинения (С. 220-221).

В последующие эпохи происходило примерно то же самое. Согласно А.Е., те, кто наделен властью по праву преемства или в результате ее завоевания или захвата, определяют правила игры, то есть отношения собственности, которые, в свою очередь, являются отношениями власти.

Логический круг в исполнении А.Е. выглядит так: те, кто обладает собственностью, обладают тем самым и властью. Власть используется для того, чтобы определять отношение собственности и тем самым назначать властителей. Собственность возникает в результате обладания властью, а власть опирается на владение собственностью.

Далее следует центральный тезис книги: «...отношения власти и собственности имеют универсальный характер, они проявляются во всех сферах человеческой деятельности. Их действия в сфере производства формируют мотивации его участников, то есть производственные отношения. Других механизмов формирования таковых мотиваций в обществе нет, а, следовательно, нет и других источников производственных отношений» (С. 232).

Обозревая состояние экономических исследований, А.Е. обращает внимание на фундаментальный методологический порок современной российской экономической науки. Он пишет: «Как очевидно, “недостаточность” модернизации в настоящий момент является следствием предшествующей слабости мотиваций субъектов, ее определяющих. Необходимо выделить этих субъектов (это могут быть госчиновники, олигархи, мелкие капиталисты, 
технократы и т.п.), оценить их роль в формировании модернизации (кто и в чем себя проявил), установить мотивации их участия в производственном процессе и причины игнорирования ими процессов модернизации. Далее следует заняться поиском путей усиления мотиваций ведущих субъектов по осуществлению процессов модернизации и введением в систему новых субъектов с высокой мотивацией» (С. 239).

Что имеет в виду А.Е., понять затруднительно; возможно, он предлагает производить ротацию - назначать одних олигархов и чиновников взамен других? А как переменить мотивации? Приучать волков к вегетарианской пище? А.Е. видит решение проблемы модернизации экономики в изменении производственных отношений. Получается, что производственные отношения поддаются манипуляции. Эта позиция также далека от марксистской доктрины.

В шестой, заключительной главе, А.Е. осуществляет разработку теории способов производства применительно к эпохе советской экономики в 1960-1980-х годах. Для этой цели он создает типологические таблицы, напоминающие периодическую таблицу химических элементов Менделеева.

Чтобы определиться с вопросом о типе советской экономики, А.Е. делает обзор классификаций, которые можно найти в российской литературе. Спектр найденных им оценок довольно широк, начиная от государственного социализма до государственного капитализма. Сам он склоняется к последнему определению (С. 270-273).

Определив советскую экономическую систему как государственный капитализм, А.Е. испытывает некоторое неудобство. Как он сам пишет, важнейшей характеристикой капиталистического способа производства и родственного ему государственного капитализма является высокая способность к массовому использованию достижений научно-технического прогресса. Однако советская экономическая система как раз продемонстрировала свою низкую эффективность в этой сфере деятельности. Чем это объяснить?

А.Е. объясняет это так: причины неэффективности советского государственного капитализма состоят в том, что имело место несоответствие сущности и формы советской экономической системы. В результате этого несоответствия были утеряны или ослаблены принципиально важные внутренние капиталистические институты. Вместо этого были приобретены внешние псевдосоциалистические качества.

Более подробного или ясного объяснения в книге мы не найдем.

\section{Чего в книге нет}

Часто бывает так, что отсутствие чего-то проясняет ситуацию лучше всего. С обсуждаемой книгой, похоже, дело обстоит именно так. Подбор «правильных» источников и/или подходящих цитат - вот основной прием данной книги. Серьезная дискуссия отсутствует. И это плохо.

Однако прежде чем перейти к обсуждению литературных источников и самой парадигмы, которой придерживается А.Е., рассмотрим выбор объекта и метода исследования. Объектом исследований А.Е. являются одни слова, а результатом их обработки - другие слова. Этот прием был типичен для ортодоксальной советской политической экономии. Реальной экономики для таких исследований не существовало. В книге можно обнаружить единственный вид деятельности, описание которого используется для иллюстрации неких тезисов, - охота на мамонта. Возможно, А.Е. и первоклассный охотник, но уж на мамонта он точно не охотился. Не делал этого и никто из ныне живущих людей. Описаний этой деятельности также не существует, если не считать нескольких наскальных росписей. Следовательно, приведенные доказательства проверке не подлежат.

Значит ли это, что развиваемые в книге рассуждения теоретическими (то есть фальсифицируемыми ${ }^{3}$ ) не являются? Нет, несмотря на обильное цитирование, А.Е. все же занимался не чистой схоластикой. Его теорию можно протестировать путем не только внутренней проверки на непротиворечивость, на отсутствие подмены понятий и ошибок наподобие порочных логических кругов (когда в исходные посылки тайком закладывается тот тезис, который подлежит доказательству). Ее можно

3 Здесь мы подразумеваем критерий К. Поппера. Теория удовлетворяет этому критерию (является фальсифицируемой и, соответственно, научной) в том случае, если существует методологическая возможность её опровержения путём постановки того или иного эксперимента, даже если такой эксперимент ещё не был поставлен. 
сопоставить, во-первых, с базовой теорией, от которой А.Е. отталкивался, и, во-вторых, с конкурирующими гипотезами.

Теория А.Е. отталкивается от экономической доктрины К. Маркса. Из марксистской модели были изъяты анализ отношений распределения, трудовая теория стоимости, устранены концепции рабочей силы и ее эксплуатации, капитала, а также механизма его расширенного воспроизводства.

В модель Маркса привнесен универсальный объясняющий принцип стремления людей к господству над слабыми и их готовности к подчинению более сильным, а также несколько более мелких деталей, как, например, принцип двойственности отношений производства, различение отношений общественных и отношений социальных и т.п. В теории А.Е. присутствует также и солидарность общественных групп, определенная исключительно как единство целей, которое якобы и объединяет людей в соответствующие группы.

Рамки рецензии не позволяют развернуто и аргументированно провести сравнение двух теорий - А.Е. и Маркса. Приведем только вывод; он состоит в следующем: произведенные А.Е. модификации исходного научного материала объясняющей силы не добавили. Модель Маркса оказалась логически и исторически корректнее и сильнее модели А.Е.

Теперь обратимся к обсуждению парадигмы универсальной объясняющей силы принципа стремления людей к господству и готовности их к подчинению и встраиванию в пирамиды власти. А.Е. опирается на якобы доказанный факт биологической природы этого принципа. При этом в книге, сильно перегруженной цитатами, нашлось место только для одного высказывания биолога, а именно, В. А. Энгельгардта (см. выше). Примечательно, что в этой цитате, явно иронической, человечество принижено сравнительно с прочими представителями животного мира, а это явно подозрительно, что мы и поспешили заметить.

В эволюционной генетике получила гораздо более полное развитие другая, противоположная парадигма. В популярной статье, опубликованной раньше, чем статья В.А. Энгельгардта, выдающийся советский биолог В.П. Эфроимсон демонстрирует принципиальную важность базового инстинкта нехищнического поведения животных и людей. Выживание и прогресс человечества опираются не на волю к господству и подчинению, а на альтруизм, готовность жертвовать собой не только для защиты и блага потомства, но и для неродственных особей. «Уже у стадных животных этот тип альтруизма распространяется за пределы семьи, охватывает стаю, стадо - отсутствие чувства взаимопомощи у членов этого сообщества обрекает его на быстрое вымирание. Ведь у многих видов животных только стая, а не пара родителей способна одновременно осуществлять сигнализацию об опасности, защиту детенышей и добывание для них пищи» [Эфроимсон, 1971]. В той же статье мы находим цитату из классика теории естественного отбора Ч. Дарвина (из книги «Происхождение человека и половой отбор»): «Так как человек не может обладать добродетелями, необходимыми для блага племени, без самоотвержения, самообладания и умения терпеть, то эти качества во все времена ценились высоко и вполне справедливо». Альтруисты не были фриками.

Более современные эволюционные биологи утверждают, что нехищнические инстинкты поведения у человека еще более развиты, чем у животных. Одним из доказательств этого служит анатомическая особенность людей сравнительно с другими приматами, а именно: сильно развитые лобные доли мозга. Оказывается, лобные доли предназначены не для того, чтобы думать, они обеспечивают способность делиться благами с неродственными особями и заботиться о них.

Сказанное не должно восприниматься как отрицание факта иерархичности структур общественных отношений и стремления людей к власти и к тем благам, которые она дает. Мы всего лишь обращаем внимание на наличие более фундаментальных инстинктов, которые определяют судьбу человечества в долгосрочной перспективе. Эти инстинкты А.Е. молча отрицает, не приводя соответствующую контраргументацию и не цитируя соответствующие публикации.

Следующий не приведенный А.Е. источник - книга классика и признанного родоначальника институциональной экономической теории Т. Веблена [Веблен, 1984] ${ }^{4}$, впервые опубликованная ровно 119 лет назад. Покажем, что взгляд Т. Веблена существенно

\footnotetext{
${ }^{4}$ Заметим попутно, что к институционализму отношение у А.Е. в целом одобрительное. Тем не менее в 148 источниках, использованных в его книге, институциональные исследования представлены только в шести.
} 
расходится с представлениями А.Е., хотя оба, и Т. Веблен, и А.Е., занимались очень и очень сходными вопросами.

Предмет исследования Т. Веблена в «Теории праздного класса»-влияние хищнических инстинктов стремления к господству на развитие общества и экономики. Для Т. Веблена было важно установить происхождение и выявить проявления склонностей людей к доблестному соперничеству, стремлению к первенству и того, как это приводит к появлению хищнических форм поведения: демонстративных видов праздности и потребления, возникновению специфических вычурных особенностей моды, формированию подставной функции женщин и т.п.

Принципиально важной особенностью концепции Т. Веблена является то, что он не считает хищнические инстинкты базовыми. По его мнению, «хищничество не может стать источником средств какой-либо группы или какого-либо класса до тех пор, пока способ производства не достигнет такой степени эффективности, чтобы сверх поддержания жизни тех, кто занят добыванием средств к существованию, оставлять запас, стоящий того чтобы его отвоевывать» ${ }^{5}$ [Веблен, 1984. С. 71].

Какой человеческий инстинкт, согласно Т. Веблену, является базовым? Вот его рассуждения на этот счет: «Будучи объектом неизбежного отбора, человек является агентом деятельности. Он в его собственном понимании есть центр развертывающейся под действием побуждений деятельности - “телеологической” деятельности. Он-агент, стремящийся во всяком действии к достижению какой-либо конкретной, объективной безличной цели. В силу того, что он является таким агентом, он наделен склонностью к работе, приносящей результаты, и испытывает неприязнь к напрасным усилиям... Эту склонность или предрасположение к эффективным действиям можно назвать “инстинктом мастерства"» [Веблен, 1984. С. 68].

Данное высказывание говорит о том, что деятельностный подход приводит к выводам, противоположным тем, которые развивает в своей книге А.Е. Неудивительно отсутствие «Теории праздного класса» в списке использованной литературы.

${ }^{5}$ Отметим сходство этих рассуждений Т. Веблена с анализом Ф. Энгельса в «Происхождении семьи, частной собственности и государства», который А.Е. также ни разу не упоминал.
В завершение перечисления того, чего в книге нет, обратимся к остро критикуемому А.Е. так называемому мэйнстриму. Принято считать мэйнстримом классическую «экономикс». Эту квазинауку, устаревший архаический артефакт, и на самом деле традиционно используют в качестве учебного материала на младших курсах периферийных вузов ${ }^{6}$. Критиковать ее легко, но это все равно, что современному астроному высказываться о геоцентрической системе. Полезнее было бы поговорить о тех исследованиях, которые ведутся серьезными учеными, или хотя бы об учебниках, используемых в серьезных вузах. В качестве примера можно взять «Микроэкономику. Поведение, институты и эволюция» С. Боулза [Боулз, 2010].

Вот некоторые названия глав этого не слишком-то нового учебника (в оригинале издание состоялось в 2004 г.):

- Социальные взаимодействия и институциональный дизайн

- Провалы координации и институциональные изменения

- Обмен: контракты, нормы и власть

- Институциональная и индивидуальная эволюция

Как видим, вузовский учебник излагает те вопросы, в равнодушии к которым А.Е. несправедливо обвинил современную науку. Конечно, подходы и базовые принципы (парадигмы) в современной экономической науке и в книге А.Е. заметно различаются. В отличие от А.Е., современные экономисты занимаются поисками механизмов координации и сотрудничества, изучают причины сбоев тех или иных институциональных дизайнов, пытаются найти такие институциональные модели, которые наилучшим образом соответствуют эффективному развитию социально-экономических систем. Даже подходы в частных вопросах у современных исследователей не похожи на то, что мы видели в книге А.Е. Например, в то время как А.Е. утверждает, что при исполнении контрактных обязательств (т.е. в процессе труда, когда действия работника, согласно убеждению А.Е., становятся голой функцией) мотивация исчезает, современные

${ }^{6}$ Более того, есть серьезные основания для того чтобы считать, что эту «науку» навязывают обществу правящие классы. Есть исследования, которые показывают, что «экономикс» никогда не использовалась в качестве основы при разработке экономической политики успешных государств. «Экономикс» - это продукт, предназначенный исключительно на экспорт, это - «троянский конь», зловредный интеллектуальный вирус из арсенала экономических убийц. 
экономисты видят мощные потенциальные поведенческие эффекты, продиктованные специфическими стимулами. Например, при неполноте информации о ходе исполнения производственных обязанностей трудовая деятельность может оказаться неэффективной. Контрактные обязательства будут нарушаться, если контракт сконструирован без учета существенных эффектов. Например, эффекта оппортунизма. Если за человеком не наблюдают, а труд оплачивается повременно, в действие вступит мотивация к ослаблению качества и количества трудовых усилий. Чтобы устранить трудовой оппортунизм, контракт могут перестроить, например, поменять оплату труда с повременной на сдельную или так, чтобы работник стал собственником бизнеса, частичным или полным (пример - таксисты, работающие в компаниях, часто являются собственниками эксплуатируемых автомобилей).

Информационные эффекты могут радикально менять отношения власти. В книге А.Е. оставлена без внимания проблема «агент - принципал». Эта проблема в экономической науке возникла достаточно давно. Когда агент обладает информацией, квалификацией или навыками, от которых существенно зависит судьба бизнеса, он становится его фактическим владельцем, хотя формально и является наемным работником. Эту тему развивали выдающиеся американские институционалисты А. Берли, Г. Минз, Дж.К. Гэлбрейт и не менее выдающийся советский экономист С.М. Меньшиков. Как нетрудно догадаться, и их труды А.Е. в своей книге не использует.

Ну и, наконец, можно отметить, что для А.Е. не существует такого направления современной экономической мысли, как поведенческая и экспериментальная экономика [Тесля, 2017]. Там, в частности, исследуется проблематика отношения людей к власти и собственности. Эксперименты показывают, что чувство справедливости или сочувствия к партнеру, начальнику или подчиненному часто играет существенную роль, порой настолько сильную, что для описания поведения людей в определенных ситуациях требуется особая объяснительная модель. Отношения власти - подчинения часто работают плохо или не работают совсем. Современный менеджмент чутко реагирует на это.

Одно из новых направлений менеджмента - отказ от иерархических пирамид власти, переход к «плоским» структурам. Успешная во многих отношениях всемирно известная компания
Facebook практикует именно такую организацию для решения проектных задач. Администрация в Facebook в основном занята тем, чтобы на рабочих местах находились подходящие люди (а тех, кто набран, - постоянно обучают за счет компании), чтобы у них было все, что нужно для работы, а проектные задачи решали команды ${ }^{7}$, состоящие только из тех, кто нужен для успеха. На территории Facebook действует идеальный кибуц. Власть хозяев и начальников, господство и подчинение там не ощущаются. Вероятно, это одна из главных причин успеха компании М. Цукерберга.

\section{Почему эта книга полезна?}

Польза обсуждаемой книги происходит от того, что она является образцом построения теоретической конструкции из моноисточника, на основе одной-единственной базовой идеи. Таких трудов, насколько известно рецензенту, в литературе очень мало $^{8}$. Студентам и специалистам обсуждаемая книга может быть полезна как некий эталон, с которым можно сравнивать альтернативные подходы. Ее можно рекомендовать как учебный кейс для разбора на практических занятиях по философии экономики, менеджменту и микроэкономике.

Как уже отмечалось, «Власть и экономические отношения» напоминает о «Теории праздного класса», которую Т. Веблен написал с целью изучения извращенных форм социального поведения, возникающих под воздействием присущих людям хищнических инстинктов, в первую очередь - стремления к власти, первенству и господству. Т. Веблен позднее написал другую книгу, «Инстинкт мастерства и уровень развития технологии производства». Любопытно будет посмотреть, удастся ли А.П. Ермилову написать книгу, в которой хищнические инстинкты объясняют социально-экономический прогресс.

${ }^{7}$ Состав команд в Facebook быстро и беспроблемно меняется. Не фиксировань даже рабочие места у людей. Шкафы и столы у работников снабжены колесиками, и при переходе в другую команду они буквально переезжают с одного места на другое.

${ }^{8}$ На память приходят только книги типа «Что такое собственность» П. Прудона, с его знаменитым «собственность - это кража»; этот автор тоже почему-то обойден при цитировании в обсуждаемой книге. 


\section{Литература}

Боулз С. Микроэкономика. Поведение, институты и эволюция/ Самуэль Боулз; [пер. с англ. Букина К. А., Демидовой А. В., Карабекян Д.С., Карпова А. В., Шиловой Н. В.]. М.: Изд-во «Дело» АНХ, 2010. 576 с.

Веблен Т. Теория праздного класса. М.: Прогресс, 1984. 367 с.

Ермилов А. П. Власть и экономические отношения: деятельностный подход. Новосибирск: ИЭОПП СО РАН, 2017. 312 с.

Льюкс С. Власть: Радикальный взгляд. М.: Изд. дом ГУ ВШЭ, 2010. 239 с.

Тесля П. Н. Экспериментальная экономика - быстро растущая ветвь экономической науки // ЭКО. 2017. № 5. С. 107-124.

Эфроимсон В.П. Родословная альтруизма (Этика с позиций эволюционной генетики человека) // Новый мир. 1971. № 10.

Статья поступила 03.05.2018.

\section{Summary}

Teslia P. N. Novosibirsk State Technical University, Novosibirsk State University Archaic Reasoning about Hierarchy and Power

(on the book by A.P. Ermilov «Power and economic relations: an activity approach»)

The paper discuss the concept of the system of socio-economic relations derived from the relations of power (domination - subordination). The author of the reviewed book develops a system of categories of political economy, based on the methodology of Marx, bringing in a number of new elements and removing from it those elements that, in his assessment, are not significant. Critical review of the book shows its strengths and weaknesses. The author's concept is evaluated from the point of view of correctness of methodological requirements, as well as by comparison with alternative approaches. The activity approach, which is the basis of the study, leads the author to original results, different from the generally recognized ones. The review discusses the explanatory power of the concept proposed by the author, its completeness and consistency.

Industrial relations; domination-subordination; hierarchies; power; institutions; political economy; mainstream; behavioral and experimental Economics

\section{References}

Boulz S. (2010) Mikroekonomika. Povedenie, instituty i evolyutsiya. Moscow. Delo ANH Publ. 576 p. (In Russ.)

Veblen T. (1984) Teoriya prazdnogo klassa. Moscow. Progress Publ. 367 p. (In Russ.)

Ermilov A.P. (2017) Vlast i ekonomicheskie otnosheniya: deyatelnostnyiy podhod. Novosibirsk: IEOPP SO RAN Publ. 312 p. (In Russ.)

Lyuks S. (2010) Vlast: Radikalnyiy vzglyad. Moscow. Izdatelskii dom GU VShE Publ. 239 p. (In Russ.)

Teslya P.N. (2017) Eksperimentalnaya ekonomika - byistro rastuschaya vetv eko-nomicheskoy nauki. ECO [ECO]. No. 5. Pp. 107-124. (In Russ.)

Efroimson V.P. (1971) Rodoslovnaya altruizma (Etika s pozitsiy evolyutsionnoy genetiki cheloveka). Novyiy mir [New world magazine]. No.10. (In Russ.) 